\title{
Adherence to Rivaroxaban, Dabigatran, and Apixaban for Stroke Prevention for Newly Diagnosed and Treatment-Naive Atrial Fibrillation Patients: An Update Using 2013-2014 Data
}

\author{
Joshua D. Brown, PharmD, PhD; Anand R. Shewale, MS; and Jeffery C. Talbert, PhD
}

\begin{abstract}
BACKGROUND: Few studies have assessed adherence to non-vitamin $\mathrm{K}$ antagonist oral anticoagulants (NOACs), especially using contemporary data now that multiple NOACs are available.
\end{abstract}

OBJECTIVE: To compare adherence and treatment patterns among NOACs for stroke prevention in patients with nonvalvular atrial fibrillation (NVAF).

METHODS: Incident and treatment-naive NVAF patients were identified during 2013-2014 from a large claims database in this retrospective cohort study. Patients were included who initiated rivaroxaban, dabigatran, or apixaban within 30 days after diagnosis. Adherence to the index medication and adherence to any oral anticoagulant was assessed using the proportion of days covered (PDC) at 3,6, and 9 months. The number of switches and gaps in therapy were also evaluated. Analyses were stratified by stroke risk scores, and a logistic regression model was used to control for factors that may predict high adherence.

RESULTS: Dabigatran had lower adherence (PDC $=0.76,0.64,0.57)$ compared with rivaroxaban $(\mathrm{PDC}=0.83,0.73,0.66 ; P<0.001)$ and apixaban ( $P D C=0.82,0.72,0.66 ; P<0.001$ ) at 3,6 , and 9 months of follow-up and twice the number of switches to either other anticoagulants or antiplatelet therapy. Adherence was higher overall as stroke risk increased, and dabigatran had consistently lower adherence compared with the other NOACs. Multivariable logistic regression predicting $\mathrm{PDC} \geq 0.80$ showed rivaroxaban users with higher odds of high adherence compared with dabigatran or rivaroxaban across all time periods. Adjusted analyses showed that increasing age and comorbid hypertension and diabetes were associated with higher adherence.

CONCLUSIONS: In this real-world analysis of adherence to NOACs, rivaroxaban and apixaban had favorable unadjusted adherence profiles compared with dabigatran, while rivaroxaban users had higher odds of high adherence ( $P D C \geq 0.80$ ) among the NOACs in adjusted analyses. Clinicians and managed care organizations should consider the implications of lower adherence on clinical outcomes and quality assessment.

J Manag Care Spec Pharm. 2017;23(9):958-67

Copyright $\odot 2017$, Academy of Managed Care Pharmacy. All rights reserved.

\section{What is already known about this subject}

Non-vitamin K antagonist oral anticoagulants (NOACs) are associated with better adherence compared with warfarin therapy. Previous studies have shown lower adherence after treatment initiation with dabigatran compared with rivaroxaban or apixaban

\section{What this study adds}

Rivaroxaban users had the highest adherence at 3, 6, and 9 months after diagnosis, as measured by proportion of days covered (PDC), while dabigatran users had significantly lower adherence. Dabigatran users tended to have more switching, and among those who switched, more dabigatran users switched to other NOACs instead of to warfarin.

Initial therapy choice with dabigatran or apixaban was associated with lower odds of high adherence to anticoagulation and may be detrimental to outcomes because of interruptions in therapy.

$\mathrm{N}$ on-vitamin $\mathrm{K}$ antagonist oral anticoagulants (NOACs) have seen rapid uptake for stroke prevention in patients with nonvalvular atrial fibrillation (NVAF). ${ }^{1}$ NOACs include dabigatran, a direct thrombin inhibitor first introduced in 2010, followed by the direct factor-Xa inhibitors rivaroxaban in 2011 and apixaban in 2012. Rivaroxaban, dabigatran, and apixaban have been shown to be noninferior or superior to warfarin in efficacy to lower the risk for thromboembolism, as well as for bleed-related safety outcomes. ${ }^{2-4}$ Edoxaban, a new factor-Xa inhibitor, was also introduced in $2015 .{ }^{5}$

NOACs have many favorable characteristics compared with warfarin, including fewer drug interactions and dietary restrictions, as well as set dosing regimens. Fewer monitoring and testing requirements are also an arguable advantage of NOAC therapy compared with warfarin. ${ }^{6}$ Notably, patient and physician preferences typically prefer NOAC profiles compared with warfarin. ${ }^{7}$ By late 2013, NOACs as a class had overtaken warfarin as the treatment of choice for anticoagulation, and the market share of NOACs has continued to increase. ${ }^{1}$ Studies comparing the adherence of NOACs to warfarin have mostly shown positive results with NOACs and a tremendous burden of discontinuation with warfarin..$^{8-12}$ Considering that stroke prevention in NVAF requires prolonged anticoagulation, the finding that adherence to anticoagulation is higher with NOACs compared with warfarin may support the increased use of NOACs in this patient population.

While adherence to individual NOACs has been compared with warfarin, little is known about the relative adherence for rivaroxaban, dabigatran, and apixaban, especially in the 
U.S. population. ${ }^{13-15}$ These drugs have considerable dosing differences (once daily dosing for rivaroxaban vs. twice daily for dabigatran and apixaban), as well as varying side-effect profiles, all of which may influence adherence to therapy., ${ }^{6,15-17}$ Understanding the differences in adherence for each therapy can help inform treatment choices by patients and physicians, as well as in formulary decision making. In addition, the Pharmacy Quality Alliance (PQA) has recently endorsed a quality measure for managed care plans for adherence to NOACs in all indications (NVAF stroke prevention and venous thromboembolism prevention and treatment), potentially making the importance of adherence to NOACs a major consideration for health plans and providers in the near future. ${ }^{13,15,18}$

The purpose of this study was to update the evidence from a previous study on adherence to NOACs in a cohort of commercially insured, newly diagnosed NVAF patients in the United States, ${ }^{19}$ by comparing adherence and treatment patterns using 2013-2014 data.

\section{Methods}

\section{Cohort Selection and Data Source}

This observational cohort study used the Truven Health Analytics MarketScan database for the years 2012-2014. The MarketScan database provides administrative claims data, including medical diagnostic and procedural billing information and pharmacy fill records for those with commercial insurance linked to demographic and insurance enrollment information for each individual. The data include medical encounters for nearly 40 million persons each year and are representative of the commercially insured population in the United States. Use of the MarketScan data was approved by the University of Kentucky Institutional Review Board.

The goal was to identify treatment-naive, incident cases of NVAF. Study subjects aged $\geq 18$ years were identified who had an incident, inpatient, or outpatient diagnosis of NVAF (International Classification of Diseases, Ninth Revision, Clinical Modification code 427.31) between January 1, 2013, and September 30, 2014. The study dates were chosen to allow assessment of apixaban, which became available in late 2012, making 2013 its first full year on the market.

At least 1 additional NVAF diagnosis $\leq 30$ days after the index diagnosis was required to avoid rule-out diagnoses. Patients were required to have at least 365 days of continuous medical and pharmacy benefits with no previous NVAF diagnosis before the index NVAF diagnosis, which was the assigned index date for that subject. Patients were excluded who had any pre-index claim with an NVAF diagnosis, evidence of oral anticoagulant use, or $\geq 2$ international normalized ratio (INR) tests to achieve a treatment-naive cohort. Similar to the requirements of randomized trials and previous observational work, we also excluded patients with transient atrial fibrillation, mitral stenosis, prosthetic heart valves, hyperthyroidism, and thyrotoxicosis., ${ }^{1,20,21}$ Finally, patients were required to initiate NOAC therapy with rivaroxaban, dabigatran, or apixaban in the 30 days after diagnosis. The final cohort included patients who had at least 3 months of continuous follow-up time after index, and these patients were further categorized into subgroups having at least 6 months and at least 9 months of continuous follow-up.

\section{Medication Use}

Prescription fills for NOACs, warfarin, and antiplatelet medications were observed throughout follow-up using Generic Product Identifier codes that were linked to National Drug Code numbers. Warfarin and antiplatelet use was observed to assess switching behaviors. Because warfarin is widely available through low-cost generic programs and may be absent from pharmaceutical claims data, ${ }^{21-23}$ we considered INR tests during the follow-up period as a proxy for warfarin fills. This methodology has been shown to have high sensitivity and specificity. ${ }^{24}$ We considered patients exposed to warfarin with at least 3 INR tests within the 30 days of follow-up and imputed a days supply of 30 days for each INR test. Antiplatelets included clopidogrel, prasugrel, dipyridamole (plus or minus aspirin), and ticlopidine. Prescription aspirin was identified but is also widely used as an over-the-counter medication, which is unobserved in claims data with no proxy measures available. Medication use was classified daily for each patient using the date of the prescription fill and the days supplied value on the claim. In the presence of overlap of 2 different medications (i.e., a switch in therapy), the overlapped portion was credited to the new medication. Patients were only classified as treated with antiplatelet medications when an antiplatelet fill was present with no NOAC or warfarin overlap.

\section{Adherence Measures}

The proportion of days covered (PDC) was calculated for each patient for the index NOAC medication, as well as for any oral anticoagulant (OAC). PDC is bound between 0 and 1 and is the raw proportion of days that medication is on hand determined by the date on which the prescription was filled and the days supplied. The interval for PDC assessment started on the day of the first prescription fill plus the length of the time interval. Time intervals for measurement included 3 months (90 days), 6 months (180 days), and 9 months (270 days). For example, a patient initiating a NOAC on day 10 after diagnosis would be followed up to days 100, 190, and 280. The PDC was defined as the number of days that the index medication was on hand during the time period divided by the total number of days in the time period. The PDC for use of any OAC (warfarin or another NOAC) during the period was also calculated, which accounts for therapy switching during follow-up. So, if the same example patient had the index NOAC from day 10-39 and then filled warfarin for days 40-100, the PDC to the index 
Adherence to Rivaroxaban, Dabigatran, and Apixaban for Stroke Prevention for Newly Diagnosed and Treatment-Naive Atrial Fibrillation Patients: An Update Using 2013-2014 Data

TABLE 1 Characteristics of Study Population that Initiated NOACs

\begin{tabular}{|c|c|c|c|c|c|c|}
\hline \multirow[b]{2}{*}{ Characteristics } & \multicolumn{2}{|c|}{$\begin{array}{c}\text { Rivaroxaban } \\
\mathbf{n}=9,817\end{array}$} & \multicolumn{2}{|c|}{$\begin{array}{c}\text { Dabigatran } \\
\mathbf{n}=2,751\end{array}$} & \multicolumn{2}{|c|}{$\begin{array}{c}\text { Apixaban } \\
\mathrm{n}=2,773\end{array}$} \\
\hline & $\mathrm{n}$ & $\%$ & $\mathrm{n}$ & $\%$ & $\mathrm{n}$ & $\%$ \\
\hline \multicolumn{7}{|l|}{ Age, years } \\
\hline Mean, SD & 70.5 & 11.8 & 67.9 & 12.5 & 73.9 & 10.6 \\
\hline$<65$ & 2,850 & 29.0 & 1,049 & 38.1 & 445 & 16.0 \\
\hline $65-74$ & 2,929 & 29.8 & 779 & 28.3 & 903 & 32.6 \\
\hline$\geq 75$ & 4,038 & 41.1 & 923 & 33.6 & 1,425 & 51.4 \\
\hline \multicolumn{7}{|l|}{ Gender } \\
\hline Female & 5,586 & 56.9 & 1,701 & 61.8 & 1,499 & 54.1 \\
\hline Male & 4,231 & 43.1 & 1,050 & 38.2 & 1,274 & 45.9 \\
\hline \multicolumn{7}{|l|}{ Region } \\
\hline Northeast & 2,086 & 21.2 & 800 & 29.1 & 596 & 21.5 \\
\hline North Central & 3,062 & 31.2 & 766 & 27.8 & 874 & 31.5 \\
\hline South & 3,296 & 33.6 & 788 & 28.6 & 960 & 34.6 \\
\hline West & 1,253 & 12.8 & 369 & 13.4 & 315 & 11.4 \\
\hline Unknown & 120 & 1.2 & 28 & 1.0 & 28 & 1.0 \\
\hline \multicolumn{7}{|l|}{ Metro statistical area } \\
\hline Rural & 1,463 & 14.9 & 505 & 18.4 & 372 & 13.4 \\
\hline Urban & 8,354 & 85.1 & 2,246 & 81.6 & 2,401 & 86.6 \\
\hline \multicolumn{7}{|l|}{ Comoribidities } \\
\hline Hypertension & 6,228 & 63.4 & 1,674 & 60.9 & 1,879 & 67.8 \\
\hline Hyperlipidemia & 4,884 & 49.8 & 1,313 & 47.7 & 1,457 & 52.5 \\
\hline Heart failure & 1,027 & 10.5 & 263 & 9.6 & 331 & 11.9 \\
\hline Diabetes & 2,559 & 26.1 & 744 & 27.0 & 754 & 27.2 \\
\hline Stroke & 1,022 & 10.4 & 269 & 9.8 & 336 & 12.1 \\
\hline Bleeding & 834 & 8.5 & 209 & 7.6 & 238 & 8.6 \\
\hline Anemia & 982 & 10.0 & 252 & 9.2 & 307 & 11.1 \\
\hline Liver disease & 311 & 3.2 & 79 & 2.9 & 88 & 3.2 \\
\hline Renal disease & 663 & 6.8 & 184 & 6.7 & 287 & 10.3 \\
\hline Vascular disease & 2,981 & 30.4 & 732 & 26.6 & 949 & 34.2 \\
\hline Chronic pulmonary disease & 1,876 & 19.1 & 466 & 16.9 & 529 & 19.1 \\
\hline Rheumatic disease & 302 & 3.1 & 73 & 2.7 & 87 & 3.1 \\
\hline Peptic ulcer disease & 79 & 0.8 & 20 & 0.7 & 25 & 0.9 \\
\hline Diabetes with complications & 720 & 7.3 & 202 & 7.3 & 233 & 8.4 \\
\hline Cancer & 1,809 & 18.4 & 401 & 14.6 & 588 & 21.2 \\
\hline \multicolumn{7}{|c|}{ Charlson Comorbidity Index score } \\
\hline Mean, SD & 1.1 & 1.6 & 1.1 & 1.5 & 1.1 & 1.5 \\
\hline \multicolumn{7}{|c|}{$\mathrm{CHA}_{2} \mathrm{DS}_{2}$-VASc stroke risk score } \\
\hline Mean, SD & 2.5 & 1.7 & 2.4 & 1.7 & 2.6 & 1.7 \\
\hline Low $($ score $=0,1)$ & 2,124 & 21.6 & 776 & 28.2 & 376 & 13.6 \\
\hline High $($ score $=2,3)$ & 3,764 & 38.3 & 1,023 & 37.2 & 1,037 & 37.4 \\
\hline Very high (score $\geq 4$ ) & 3,929 & 40.0 & 952 & 34.6 & 1,360 & 49.0 \\
\hline \multicolumn{7}{|l|}{ HAS-BLED bleed risk score } \\
\hline Mean, SD & 1.5 & 1.0 & 1.4 & 1.0 & 1.5 & 1.0 \\
\hline Low $($ score $=0$ ) & 1,159 & 11.8 & 416 & 15.1 & 163 & 5.9 \\
\hline Medium (score $=1-2$ ) & 6,187 & 63.0 & 1,684 & 61.2 & 1,790 & 64.6 \\
\hline High (score $\geq 3$ ) & 2,471 & 25.2 & 651 & 23.7 & 820 & 29.6 \\
\hline
\end{tabular}

medication would be 0.33 (30 days/90 days) and the PDC to oral anticoagulation throughout the period would be 1.0. If no NOAC or warfarin was available on a particular day, that day was flagged as having no therapy. The PDC was evaluated as the mean PDC for each group, as well as divided into categories of high adherence ( $\geq 0.80)$, moderate adherence (0.50-0.79), and low adherence $(<0.50)$. Medication gaps and switches were also observed. A gap was defined when no observed OAC 


\begin{tabular}{|c|c|c|c|c|}
\hline TABLE 2 & \multicolumn{4}{|c|}{$\begin{array}{l}\text { Adherence Compa } \\
\text { Rivaroxaban, Dabi } \\
\text { Users at 3, 6, and }\end{array}$} \\
\hline \multicolumn{5}{|c|}{3 Months } \\
\hline & $\begin{array}{c}\text { Rivaroxaban } \\
\mathrm{n}=9,817\end{array}$ & $\begin{array}{c}\text { Dabigatran } \\
\mathrm{n}=2,751\end{array}$ & $\begin{array}{c}\text { Apixaban } \\
\mathrm{n}=2,773\end{array}$ & $P$ Value \\
\hline \multicolumn{5}{|l|}{$\mathrm{PDC}^{\mathrm{a}}$} \\
\hline Mean (SD) & $0.83(0.26)$ & $0.76 \quad(0.29)$ & $0.82(0.26)$ & $<0.001$ \\
\hline$\geq 0.80, \mathrm{n}(\%)$ & $6,974 \quad(71.0)$ & $1,663(60.5)$ & $1,974 \quad(71.2)$ & $<0.001$ \\
\hline $0.50-0.79, \mathrm{n}(\%)$ & $1,201 \quad(12.2)$ & $421 \quad(15.3)$ & $383(13.8)$ & \\
\hline$<0.50, \mathrm{n}(\%)$ & $1,642 \quad(16.7)$ & $667 \quad(24.3)$ & $416(15.0)$ & \\
\hline \multicolumn{5}{|l|}{ Gaps, ${ }^{b}$ n (\%) } \\
\hline$\geq 15$ days & $877 \quad(8.9)$ & $331(12.0)$ & $334(12.0)$ & $<0.001$ \\
\hline$\geq 30$ days & $326 \quad(3.3)$ & $127 \quad(4.6)$ & $127 \quad(4.6)$ & 0.018 \\
\hline$\geq 60$ days & $57 \quad(0.6)$ & $24 \quad(0.9)$ & $22 \quad(0.8)$ & 0.174 \\
\hline \multicolumn{5}{|l|}{ Switch, ${ }^{\mathrm{c}} \mathrm{n}(\%)$} \\
\hline Other OAC & $571 \quad(5.8)$ & $336(12.2)$ & $187 \quad(6.8)$ & $<0.001$ \\
\hline Antiplatelet & $199 \quad(2.0)$ & $63 \quad(2.3)$ & $50 \quad(1.8)$ & 0.438 \\
\hline \multicolumn{5}{|c|}{6 Months } \\
\hline & $\begin{array}{c}\text { Rivaroxaban } \\
\mathrm{n}=8,908\end{array}$ & $\begin{array}{c}\text { Dabigatran } \\
\mathbf{n}=2,607\end{array}$ & $\begin{array}{c}\text { Apixaban } \\
\mathrm{n}=2,329\end{array}$ & $P$ Value \\
\hline \multicolumn{5}{|l|}{$\mathrm{PDC}^{\mathrm{a}}$} \\
\hline Mean (SD) & $0.73 \quad(0.32)$ & $0.64 \quad(0.34)$ & $0.72 \quad(0.31)$ & $<0.001$ \\
\hline$\geq 0.80, \mathrm{n}(\%)$ & $5,300 \quad(59.5)$ & $1,245 \quad(47.8)$ & $1,398 \quad(60.0)$ & $<0.001$ \\
\hline $0.50-0.79, \mathrm{n}(\%)$ & $1,569 \quad(17.6)$ & $524 \quad(20.1)$ & $454 \quad(19.5)$ & \\
\hline$<0.50, \mathrm{n}(\%)$ & $2,039 \quad(22.9)$ & $838 \quad(32.1)$ & $477(20.5)$ & \\
\hline \multicolumn{5}{|l|}{ Gaps, ${ }^{b}$ n (\%) } \\
\hline$\geq 15$ days & $1,538 \quad(17.1)$ & $612(23.5)$ & $550 \quad(23.4)$ & $<0.001$ \\
\hline$\geq 30$ days & $790 \quad(8.8)$ & $319(12.2)$ & $293(12.5)$ & $<0.001$ \\
\hline$\geq 60$ days & $276 \quad(3.1)$ & $118 \quad(4.5)$ & $95 \quad(4.1)$ & 0.022 \\
\hline \multicolumn{5}{|l|}{ Switch, ${ }^{\mathrm{c}}$ n (\%) } \\
\hline Other OAC & $735 \quad(8.2)$ & $445 \quad(17.1)$ & $214 \quad(9.1)$ & $<0.001$ \\
\hline Antiplatelet & $261 \quad(2.9)$ & $100 \quad(3.8)$ & $\begin{array}{ll}69 & (2.9) \\
\end{array}$ & 0.044 \\
\hline \multicolumn{5}{|c|}{9 Months } \\
\hline & $\begin{array}{c}\begin{array}{c}\text { Rivaroxaban } \\
\mathbf{n}=7,969\end{array} \\
\end{array}$ & $\begin{array}{c}\text { Dabigatran } \\
\mathrm{n}=2,456\end{array}$ & $\begin{array}{c}\text { Apixaban } \\
\mathrm{n}=1,858\end{array}$ & $P$ Value \\
\hline \multicolumn{5}{|l|}{$\mathrm{PDC}^{\mathrm{a}}$} \\
\hline Mean (SD) & $0.66 \quad(0.34)$ & $0.57 \quad(0.35)$ & $0.66 \quad(0.33)$ & $<0.001$ \\
\hline$\geq 0.80, \mathrm{n}(\%)$ & $3,753 \quad(47.1)$ & $912 \quad(37.1)$ & $889 \quad(47.9)$ & $<0.001$ \\
\hline $0.50-0.79, \mathrm{n}(\%)$ & $1,421 \quad(17.8)$ & 432 (17.6) & $356 \quad(19.2)$ & \\
\hline$<0.50, \mathrm{n}(\%)$ & $2,795 \quad(35.1)$ & $1,112 \quad(45.3)$ & $613(33.0)$ & \\
\hline \multicolumn{5}{|l|}{ Gaps, ${ }^{b}$ n (\%) } \\
\hline$\geq 15$ days & $1,578 \quad(20.8)$ & $591 \quad(25.3)$ & $482 \quad(27.3)$ & $<0.001$ \\
\hline$\geq 30$ days & 902 (11.9) & $335 \quad(14.3)$ & $280 \quad(15.9)$ & $<0.001$ \\
\hline$\geq 60$ days & $408 \quad(5.4)$ & $158 \quad(6.8)$ & $111 \quad(6.3)$ & 0.052 \\
\hline \multicolumn{5}{|l|}{ Switch, ${ }^{\mathrm{c}} \mathrm{n}(\%)$} \\
\hline Other OAC & $719 \quad(9.5)$ & $440 \quad(18.8)$ & $185(10.5)$ & $<0.001$ \\
\hline Antiplatelet & $256 \quad(3.4)$ & $90 \quad(3.9)$ & $60 \quad(3.4)$ & 0.538 \\
\hline
\end{tabular}

aPDC $=$ sum of days supply from initiation of therapy to the end of the time period divided by time period length $(90,180$, or 270 days). Prescription fills were corrected for early refills and credited to the numerator.

${ }^{b}$ Gaps were any period where no treatments (OAC or antiplatelet) were observed. Gap lengths $(15,30,60$ days) were not mutually exclusive.

"Individuals with a switch or a gap who reinitiated the index medication after the gap or switch and within the time period.

$O A C=$ oral anticoagulant $P D C=$ proportion of days covered $S D=$ standard deviation. therapy was present, either no treatment or only antiplatelet therapy. While gaps are also inherent in the PDC calculation, gaps of at least 15 days, 30 days, and 60 days were noted for each patient.

\section{Study Variables}

Demographics including age, gender, region, and rural/urban residence were assessed on the index date. Baseline stroke and bleed risk scores were calculated based on the 365-day pre-index period. Stroke risk was assessed using the $\mathrm{CHA}_{2} \mathrm{DS}_{2}$ VASc score. ${ }^{25} \mathrm{CHA}_{2} \mathrm{DS}_{2}$-VASc scores were stratified by low (0 points), moderate (1 point), high (2-3 points), and very high $(\geq 4$ points) stroke risk and included 1 point each for heart failure, hypertension, age 65-74 years, diabetes, peripheral vascular disease, female gender, and 2 points each for history of stroke and age $\geq 75$ years. HAS-BLED scores were used for bleed risk and included 1 point each for hypertension, renal disease, liver disease, stroke history, previous bleeding, age $\geq 65$ years, antiplatelet or nonsteroidal anti-inflammatory drug use, and alcohol or drug use and were stratified as low risk $($ score $=0)$, moderate risk (score $=1$ ), and high risk $($ score $\geq 2){ }^{26}$ HAS-BLED includes a point for labile INR tests, which is not observable in the dataset but would not be important for treatment-naive, incident cases. A Charlson Comoribidity Index (CCI) score was also computed for each subject and summarized as the sum of the weighted scores. ${ }^{27}$

\section{Statistical Analyses}

Treatment group demographic and clinical characteristics were compared using analysis of variance and chi-square or Fisher's exact tests for continuous and categorical variables, respectively. Multiple logistic regression models were estimated, which included all specified baseline variables and the treatment group assignment predicting the probability of having a high adherence (PDC $\geq 0.80$ ) to NOACs or any OAC at 3, 6, and 9 months of follow-up. Odds ratios and 95\% confidence intervals were reported from these models. Operationalized definitions of all diagnosis, procedure, and medication codes are included in Appendix A (available in online article). All analyses were conducted using SAS Enterprise Guide version 7.1 (SAS Institute, Cary, NC).

\section{Results}

\section{Comparison of Treatment Groups}

After inclusion and exclusion, 9,817 rivaroxaban, 2,751 dabigatran, and 2,773 apixaban users were identified during the study period who had at least 3 months of continuous follow-up after NVAF diagnosis (Appendix B, available in online article). Treatment selection differed greatly between the 2 study years. In 2013, of the 10,873 patients that received NOACs, $65.3 \%$ received rivaroxaban; $22.1 \%$ received dabigatran; and $12.6 \%$ received apixaban. In 2014 , for 4,468 treated patients, $60.9 \%$ 


\begin{tabular}{|c|c|c|c|c|}
\hline TABLE 3 & \multicolumn{4}{|c|}{$\begin{array}{l}\text { Adherence Comparison of Index } \\
\text { Medication Among Patients with High } \\
\text { and Very High Stroke Risk }\end{array}$} \\
\hline \multicolumn{5}{|c|}{3 Months } \\
\hline & Rivaroxaban & Dabigatran & Apixaban & $P$ Value \\
\hline \multicolumn{5}{|c|}{$\mathrm{CHA}_{2} \mathrm{DS}_{2}-\mathrm{VASc}=2$ or 3} \\
\hline \multicolumn{5}{|l|}{ PDC } \\
\hline Mean (SD) & $0.84(0.25)$ & $0.79(0.28)$ & $0.83(0.26)$ & $<0.001$ \\
\hline$\geq 0.80, \mathrm{n}(\%)$ & $2,796(74.3)$ & $663(64.8)$ & $760(73.3)$ & $<0.001$ \\
\hline $0.50-0.79, \mathrm{n}(\%)$ & $394(10.5)$ & $140(13.7)$ & $139(13.4)$ & \\
\hline$<0.50, \mathrm{n}(\%)$ & $574(15.3)$ & $220(21.5)$ & $138(13.3)$ & \\
\hline \multicolumn{5}{|l|}{$\mathrm{CHA}_{2} \mathrm{DS}_{2}-\mathrm{VASc} \geq 4$} \\
\hline \multicolumn{5}{|l|}{ PDC } \\
\hline Mean (SD) & $0.87(0.24)$ & $0.78(0.30)$ & $0.85(0.24)$ & $<0.001$ \\
\hline$\geq 0.80, \mathrm{n}(\%)$ & $2,998(76.3)$ & $609(64.0)$ & $1,019(74.9)$ & $<0.001$ \\
\hline $0.50-0.79, \mathrm{n}(\%)$ & $421(10.7)$ & $131(13.8)$ & $173(12.7)$ & \\
\hline$<0.50, \mathrm{n}(\%)$ & $510(13.0)$ & $212(22.3)$ & $168(12.4)$ & \\
\hline \multicolumn{5}{|c|}{6 Months } \\
\hline \multicolumn{5}{|c|}{$\mathrm{CHA}_{2} \mathrm{DS}_{2}-\mathrm{VASc}=2$ or 3} \\
\hline \multicolumn{5}{|l|}{$\mathrm{PDC}$} \\
\hline Mean (SD) & $0.75(0.31)$ & $0.68(0.33)$ & $0.74(0.30)$ & $<0.001$ \\
\hline$\geq 0.80, \mathrm{n}(\%)$ & $2,196(64.1)$ & $511(52.5)$ & $546(62.5)$ & $<0.001$ \\
\hline $0.50-0.79, \mathrm{n}(\%)$ & $541(15.8)$ & $188(19.3)$ & $163(18.7)$ & \\
\hline$<0.50, \mathrm{n}(\%)$ & $687(20.1)$ & $274(28.2)$ & $165(18.9)$ & \\
\hline \multicolumn{5}{|l|}{$\mathrm{CHA}_{2} \mathrm{DS}_{2}-\mathrm{VASc} \geq 4$} \\
\hline \multicolumn{5}{|l|}{ PDC } \\
\hline Mean (SD) & $0.79(0.29)$ & $0.68(0.34)$ & $0.78(0.28)$ & $<0.001$ \\
\hline$\geq 0.80, \mathrm{n}(\%)$ & $2,301 \quad(66.4)$ & $474(53.6)$ & $726(65.5)$ & $<0.001$ \\
\hline $0.50-0.79, \mathrm{n}(\%)$ & $594(17.1)$ & $159(18.0)$ & $216(19.5)$ & \\
\hline$<0.50, \mathrm{n}(\%)$ & $573(16.5)$ & $252(28.5)$ & $166(15.0)$ & \\
\hline \multicolumn{5}{|c|}{9 Months } \\
\hline \multicolumn{5}{|c|}{$\mathrm{CHA}_{2} \mathrm{DS}_{2}-\mathrm{VASc}=2$ or 3} \\
\hline \multicolumn{5}{|l|}{$\mathrm{PDC}$} \\
\hline Mean (SD) & $0.69(0.34)$ & $0.61(0.35)$ & $0.68(0.33)$ & $<0.001$ \\
\hline$\geq 0.80, \mathrm{n}(\%)$ & $1,591(52.5)$ & $382(41.9)$ & $340(48.9)$ & $<0.001$ \\
\hline $0.50-0.79, \mathrm{n}(\%)$ & $501(16.5)$ & $167(18.3)$ & $144(20.7)$ & \\
\hline$<0.50, \mathrm{n}(\%)$ & $937(30.9)$ & $362(39.7)$ & $211(30.4)$ & \\
\hline \multicolumn{5}{|l|}{$\mathrm{CHA}_{2} \mathrm{DS}_{2}-\mathrm{VASc} \geq 4$} \\
\hline \multicolumn{5}{|l|}{ PDC } \\
\hline Mean (SD) & $0.73(0.32)$ & $0.62(0.35)$ & $0.74(0.30)$ & $<0.001$ \\
\hline$\geq 0.80, \mathrm{n}(\%)$ & $1,695(56.8)$ & $363(44.4)$ & $492(58.5)$ & $<0.001$ \\
\hline $0.50-0.79, \mathrm{n}(\%)$ & $539(18.1)$ & $144(17.6)$ & $149(17.7)$ & \\
\hline$<0.50, \mathrm{n}(\%)$ & $751(25.2)$ & $310(37.9)$ & $200(23.8)$ & \\
\hline \multicolumn{5}{|c|}{$\begin{array}{l}\text { Note: } P D C=\text { sum of days supply from initiation of therapy during the time period } \\
\text { divided by time period length }(90,180 \text {, or } 270 \text { days). Prescription fills were } \\
\text { corrected for early refills and credited to the numerator. } \\
\text { PDC=proportion of days covered; } S D=\text { standard deviation. }\end{array}$} \\
\hline
\end{tabular}

received rivaroxaban; $7.8 \%$ received dabigatran; and 31.3\% received apixaban, showing a large decrease in the dabigatran market share and increases in apixaban market share. Table 1 shows the baseline characteristics of each treatment group. There were a few differences between the populations, such as nonsignificant counts of comorbidities, gender, rural/urban status, and no significant differences in $\mathrm{CHA}_{2} \mathrm{DS}_{2}-\mathrm{VASc}$ or
HAS-BLED scores. Age differences were observed, with apixaban having an average of a 3-year higher age compared with rivaroxaban and almost 6 years higher age than dabigatran users, driven by a higher proportion of users aged $\geq 75$ years. The distribution of region among treatment groups was also different. At 6 months, $90.2 \%(n=13,844)$ of the sample remained, and at 9 months, $80.1 \%(n=12,283)$ of the sample remained. Characteristics were observed for those remaining in the cohort at 6 and 9 months, and similar distributions were observed with no significant differences for these subgroups.

\section{Adherence to Treatment}

At 3 months of follow-up after treatment initiation, the mean PDC was $0.83,0.76$, and 0.82 for rivaroxaban, dabigatran, and apixaban $(P<0.001)$, respectively (Table 2$)$. Rivaroxaban users had the highest proportion $(71 \%)$ of users with high adherence (PDC $\geq 0.80$ ). Dabigatran and apixaban users tended to have more gaps in therapy relative to the rivaroxaban group. Compared with rivaroxaban and apixaban users, dabigatran users also had 2 times the proportion of patients who switched to another OAC $(12.2 \%$ vs. $5.8 \%$ and $6.8 \%, P<0.001)$. Similar patterns were observed at 6 months of follow-up. Rivaroxaban and apixaban users had similar PDCs, while dabigatran users had significantly lower average PDCs $(P<0.001)$, as well as a higher proportion of users who switched to another OAC $(17.1 \%$ vs. $8.2 \%$ and $9.1 \%, P<0.001)$. After 9 months, average adherence to rivaroxaban $(P D C=0.66)$ and apixaban $(P D C=0.66)$ were significantly higher than dabigatran (PDC $=0.57, P<0.001)$.

Less than half of all NOAC users had adherence of $P D C \geq 0.80$, regardless of treatment choice. Among all observed OAC switches for rivaroxaban users, $65.1 \%$ were to warfarin; $11.9 \%$ were to dabigatran; and $23.1 \%$ were to apixaban. For dabigatran users, $40.1 \%$ of all OAC switches were to warfarin; $46.9 \%$ were to rivaroxaban; and $13.1 \%$ were to apixaban. Apixaban switches included $45.6 \%$ to warfarin, $46.9 \%$ to rivaroxaban, and $7.5 \%$ to dabigatran.

Adherence was also evaluated among those with high and very high stroke risk scores, since guidelines strongly recommend long-term OAC thromboprophylaxis for these subgroups (Table 3). ${ }^{27,28}$ Adherence was marginally higher among those patients with comparable adherence to rivaroxaban and apixaban and lower adherence for dabigatran. Adherence to any OAC over the time period was also evaluated for the overall cohort, as well as stratified by stroke risk scores (Table 4). Adherence increased across all treatment groups with increasing stroke risk scores and was higher than adherence considering only index medications. Rivaroxaban and apixaban users tended to have higher PDCs to any OACs compared with dabigatran across stroke risk categories. 


\begin{tabular}{|c|c|c|c|c|}
\hline BL & \multicolumn{4}{|c|}{$\begin{array}{l}\text { PDCs for Any OAC for Each Treatment } \\
\text { Group Stratified by Stroke Risk Scores }\end{array}$} \\
\hline \multicolumn{5}{|c|}{3 Months } \\
\hline ean (SD) & $\begin{array}{c}\text { Rivaroxaban } \\
\mathbf{n}=9,817\end{array}$ & $\begin{array}{c}\text { Dabigatran } \\
\mathrm{n}=2,751\end{array}$ & $\mathrm{n}=2,773$ & $\begin{array}{c}P \\
\text { Value }\end{array}$ \\
\hline verall & $0.85 \quad(0.24)$ & $0.82(0.25)$ & $0.85 \quad(0.23)$ & $<0.001$ \\
\hline 0,1 & $0.76(0.28)$ & $0.75(0.27)$ & $0.74 \quad(0.28)$ & 0.307 \\
\hline 2,3 & $0.86 \quad(0.23)$ & $0.84(0.23)$ & $0.86 \quad(0.22)$ & 0.048 \\
\hline 4 & $0.89 \quad(0.21)$ & $0.86(0.23)$ & $0.87 \quad(0.21)$ & 0.033 \\
\hline \multicolumn{5}{|c|}{6 Months } \\
\hline $\operatorname{an}(\mathrm{SD})$ & $\begin{array}{c}\text { Rivaroxaban } \\
\mathbf{n}=8,908\end{array}$ & $\begin{array}{c}\text { Dabigatran } \\
\mathrm{n}=2,607\end{array}$ & $\begin{array}{c}\text { Apixaban } \\
\mathrm{n}=2,329\end{array}$ & $\begin{array}{c}P \\
\text { Value }\end{array}$ \\
\hline verall & $0.75(0.30)$ & $0.72(0.30)$ & $0.76(0.28)$ & $<0.001$ \\
\hline $\mathrm{HA}_{2} \mathrm{DS}$ & $0.62 \quad(0.33)$ & $0.60(0.32)$ & $0.57 \quad(0.32)$ & 0.061 \\
\hline$=2,3$ & $0.78 \quad(0.29)$ & $0.76(0.28)$ & $0.78 \quad(0.27)$ & 0.041 \\
\hline -VASc $\geq 4$ & $0.82(0.26)$ & $0.79 \quad(0.27)$ & $0.82 \quad(0.24)$ & 0.023 \\
\hline \multicolumn{5}{|c|}{9 Months } \\
\hline $\begin{array}{l}\text { IC PDCs, } \\
\text { ean (SD) }\end{array}$ & $\begin{array}{c}\text { Rivaroxaban } \\
\mathbf{n}=7,969\end{array}$ & $\begin{array}{c}\text { Dabigatran } \\
\mathrm{n}=2,456\end{array}$ & $\begin{array}{c}\text { Apixaban } \\
\mathrm{n}=1,858\end{array}$ & $\begin{array}{c}P \\
\text { Value }\end{array}$ \\
\hline Overall & $0.69 \quad(0.33)$ & $0.66 \quad(0.32)$ & $0.70 \quad(0.31)$ & $<0.001$ \\
\hline $\mathrm{HA}_{2} \mathrm{DS}_{2}-\mathrm{VASc}=0,1$ & $0.51 \quad(0.33)$ & $0.50 \quad(0.33)$ & $0.45 \quad(0.31)$ & 0.049 \\
\hline$=2,3$ & $0.72 \quad(0.32)$ & $0.70 \quad(0.31)$ & $0.72(0.30)$ & 0.011 \\
\hline $\mathrm{CHA}_{2} \mathrm{DS}_{2}-\mathrm{VASc} \geq 4$ & $0.77(0.29)$ & $0.74 \quad(0.29)$ & $0.78 \quad(0.27)$ & 0.022 \\
\hline
\end{tabular}

Note: $P D C=$ sum of days supply from initiation of therapy during time period divided by time period length (90, 180, or 270 days). Prescription fills were corrected for early refills and credited to the numerator. A day was considered to have anticoagulant therapy if warfarin, rivaroxaban, dabigatran, or apixaban was available for that day.

$O A C=$ oral anticoagulant $P D C=$ proportion of days covered; $S D=$ standard deviation.

\section{Regression Results}

Multiple logistic models were used to control for any residual differences between the treatment groups at each follow-up interval. Baseline characteristics along with treatment group were included in the model predicting the probability of having high adherence to the index medication and to all OACs (PDC $\geq 0.80$; Table 5). Individual items of the stroke and bleed risk scores were included separately as separate covariates so that their effects would not be absorbed by the composite scores.

The primary comparison was the effect of treatment group assignment on adherence. As shown in uncontrolled analyses, rivaroxaban users were consistently more adherent to their index therapies. This trend persisted for OAC adherence until 9 months of follow-up. Comparisons between apixaban and rivaroxaban produced point estimates showing an advantage in adherence with rivaroxaban in that apixaban users had 4\%-23\% lower odds of having high adherence compared with rivaroxaban. This comparison was stronger for dabigatran compared with rivaroxaban, with dabigatran users having 27\%-39\% lower odds of high adherence compared with rivaroxaban. The pairwise comparison between dabigatran and apixaban also showed a decrement in adherence with dabigatran users compared with apixaban users.
Increasing age was a consistent significant predictor of high adherence, increasing the odds of adherence among patients aged 65-74 years and $\geq 75$ years by roughly $150 \%-350 \%$ compared with patients aged $<65$ years. Presence of hypertension, cancer, hyperlipidemia, or diabetes also increased the odds of high adherence. Increasing comorbidity burden, measured by the CCI, was negatively associated with adherence.

\section{Discussion}

Among the commercially insured NVAF patients in the United States, this study found consistently lower adherence for dabigatran compared with rivaroxaban and apixaban. Results suggest that rivaroxaban also has a slight advantage in adherence when compared with apixaban, which was more pronounced after adjusting for baseline characteristics. These findings persisted for the overall cohort, as well as for the subgroups of patients at high and very high risk of stroke according to baseline $\mathrm{CHA}_{2} \mathrm{DS}_{2}$-VASc scores. Using a cut-off of PDC $\geq 0.80$ to distinguish adherent individuals, this translated into an absolute difference of roughly $10 \%$ fewer dabigatran users meeting this cutpoint compared with either rivaroxaban or apixaban users. Differences between rivaroxaban and apixaban users existed but were either not consistent or not significant in all analyses.

The decrement in adherence to dabigatran was also observed in the adherence analysis to any OAC over the treatment periods. This measure is most important among those patients with $\mathrm{CHA}_{2} \mathrm{DS}_{2}$-VASc scores $\geq 2$, since guidelines routinely recommend long-term OACs for stroke prevention. ${ }^{28,29}$ Measuring PDC for any OAC takes into account switching between NOACs or warfarin and serves as a proxy measure of adherence to treatment guidelines. These results further showed that rivaroxaban and apixaban treatment groups did not differ in OAC adherence, while dabigatran users tended to have lower adherence compared with these groups. These findings suggest that initiation of dabigatran as initial treatment can effect long-term treatment adherence, even when allowing for switching. More research is needed to understand this effect and to systematically assess the outcomes associated with these findings.

Adherence and/or persistence to NOACs has mostly been assessed for single products or compared with warfarin, and a few studies have assessed these measures in the United States. ${ }^{8,10-12,30,31}$ Existing studies have mostly focused on dabigatran, since it was marketed first, and rivaroxaban and have shown similar results as our study. As in our study, adherence to therapy was associated with increased age, as well as increased stroke risk. ${ }^{9,10}$

Although our findings are consistent with the previous studies, it was important to consider adherence and switching concurrently for NOACs now that multiple treatment options are available. A recent study by Crivera et al. (2015) assessed PDC for NOACs in a large managed care database. ${ }^{14}$ They found that approximately $75 \%$ of rivaroxaban users, $70 \%$ of apixaban 


\section{TABLE 5 Multivariable Logistic Regression Results Predicting High Adherence ${ }^{a}$}

\begin{tabular}{|c|c|c|c|c|c|c|c|c|c|}
\hline \multicolumn{10}{|c|}{ PDC $\geq 0.80$ to Index NOAC } \\
\hline & \multicolumn{3}{|c|}{3 Months } & \multicolumn{3}{|c|}{6 Months } & \multicolumn{3}{|c|}{9 Months } \\
\hline & OR & \multicolumn{2}{|c|}{$95 \% \mathrm{CL}$} & OR & \multicolumn{2}{|c|}{$95 \% \mathrm{CL}$} & OR & \multicolumn{2}{|c|}{$95 \% \mathrm{CL}$} \\
\hline \multicolumn{10}{|l|}{ Index medication } \\
\hline Dabigatran vs. rivaroxaban & 0.67 & 0.61 & 0.73 & 0.66 & 0.60 & 0.72 & 0.70 & 0.63 & 0.77 \\
\hline Apixaban vs. rivaroxaban & 0.87 & 0.79 & 0.96 & 0.87 & 0.79 & 0.96 & 0.86 & 0.77 & 0.96 \\
\hline Dabigatran vs. apixaban ${ }^{\mathrm{b}}$ & 0.76 & 0.68 & 0.86 & 0.75 & 0.67 & 0.84 & 0.81 & 0.71 & 0.93 \\
\hline \multicolumn{10}{|c|}{ Demographic and clinical characteristics } \\
\hline Aged $65-74$ years vs. $<65$ years & 2.60 & 2.36 & 2.85 & 3.11 & 2.83 & 3.42 & 4.69 & 4.22 & 5.21 \\
\hline Aged $\geq 75$ years vs. $<65$ years & 2.47 & 2.25 & 2.71 & 3.06 & 2.79 & 3.36 & 4.79 & 4.32 & 5.32 \\
\hline Hypertension & 1.20 & 1.11 & 1.30 & 1.18 & 1.10 & 1.28 & 1.19 & 1.09 & 1.29 \\
\hline Diabetes & 1.24 & 1.11 & 1.38 & 1.30 & 1.17 & 1.45 & 1.29 & 1.15 & 1.45 \\
\hline Charlson Comorbidity Index & 0.92 & 0.88 & 0.96 & 0.91 & 0.87 & 0.95 & 0.92 & 0.88 & 0.96 \\
\hline Hyperlipidemia & 1.16 & 1.07 & 1.25 & 1.04 & 0.97 & 1.12 & 1.04 & 0.96 & 1.12 \\
\hline Cancer & 1.24 & 1.09 & 1.42 & 1.22 & 1.07 & 1.39 & 1.20 & 1.05 & 1.39 \\
\hline \multicolumn{10}{|c|}{ PDC $\geq 0.80$ to All OACs } \\
\hline & \multicolumn{3}{|c|}{3 Months } & \multicolumn{3}{|c|}{6 Months } & \multicolumn{3}{|c|}{9 Months } \\
\hline & OR & \multicolumn{2}{|c|}{$95 \% \mathrm{CL}$} & OR & \multicolumn{2}{|c|}{$95 \% \mathrm{CL}$} & OR & \multicolumn{2}{|c|}{$95 \% \mathrm{CL}$} \\
\hline \multicolumn{10}{|l|}{ Index medication } \\
\hline Dabigatran vs. rivaroxaban & 0.82 & 0.74 & 0.90 & 0.84 & 0.76 & 0.92 & 0.90 & 0.82 & 1.00 \\
\hline Apixaban vs. rivaroxaban & 0.92 & 0.91 & 0.93 & 0.88 & 0.80 & 0.97 & 0.86 & 0.78 & 0.96 \\
\hline Dabigatran vs. apixaban ${ }^{\mathrm{b}}$ & 0.92 & 0.82 & 1.04 & 0.95 & 0.84 & 1.07 & 1.05 & 0.92 & 1.19 \\
\hline \multicolumn{10}{|c|}{ Demographic and clinical characteristics } \\
\hline Aged $65-74$ years vs. $<65$ years & 2.94 & 2.66 & 3.24 & 3.60 & 3.27 & 3.97 & 5.43 & 4.89 & 6.04 \\
\hline Aged $\geq 75$ years vs. $<65$ years & 2.70 & 2.45 & 2.97 & 3.40 & 3.09 & 3.74 & 5.28 & 4.76 & 5.85 \\
\hline Hypertension & 1.23 & 1.14 & 1.33 & 1.23 & 1.13 & 1.33 & 1.14 & 1.35 & 1.14 \\
\hline Diabetes & 1.24 & 1.11 & 1.39 & 1.27 & 1.14 & 1.42 & 1.13 & 1.43 & 1.13 \\
\hline Charlson Comorbidity Index & 0.92 & 0.87 & 0.96 & 0.91 & 0.87 & 0.95 & 0.92 & 0.87 & 0.96 \\
\hline Hyperlipidemia & 1.21 & 1.12 & 1.31 & 1.06 & 1.06 & 1.15 & 1.02 & 0.94 & 1.11 \\
\hline Cancer & 1.28 & 1.12 & 1.48 & 1.16 & 1.02 & 1.33 & 1.19 & 1.03 & 1.37 \\
\hline
\end{tabular}

Note: The full cohort was included in each model with no missing variables for any subjects. Other variables included in the model with nonsignificant effects: gender, urban/rural status, region, history of stroke, vascular disease, renal disease, liver disease, prior bleeding or medications that increase risk of bleeding, alcohol abuse, and dementia. $\mathrm{CHA}_{2} D \mathrm{~S}_{2}$-VASc and HAS-BLED scores were expanded to individual variables rather than summarized scores.

${ }^{a}$ High adherence $=P D C \geq 0.80$.

bAttained using the same model and changing the reference treatment group to apixaban.

$C L=$ confidence limit; $N O A C=$ non-vitamin $\mathrm{K}$ oral anticoagulant; $O A C=$ oral anticoagulant; $O R=$ odds ratio; $P D C=$ proportion of days covered.

users, and $67 \%$ of dabigatran users were highly adherent to therapy over a 1-year period. These values are higher than the proportions found in our study and also showed a larger difference between rivaroxaban and apixaban. Their methodology used a distinct algorithm for identifying users according to standardized methods and was also not specific to NVAF, since they considered NOAC adherence across all indications. Their findings are consistent with our study, however, showing dabigatran with lower overall adherence compared with both comparators. ${ }^{14}$ Our study is an update of a previous study by our group, which used data from 2013 to assess adherence to NOACs. ${ }^{19}$ Overall, results of the previous study are similar to the current study, although a slightly larger advantage for rivaroxaban versus apixaban was observed using the updated data.
The switching patterns observed in our study also suggest some differences in patient and physician preferences. While more dabigatran users switched therapy compared with the other groups, a larger proportion switched to another NOAC instead of warfarin. Similarly, most apixaban users switched to another NOAC, while a large majority of rivaroxaban users switched to warfarin. This may be because of the once daily dosing of rivaroxaban and warfarin, which has been shown to be an important consideration for patients and physicians and may be even more important for patients who tend to be less adherent. ${ }^{7,16}$

Adherence to anticoagulation therapy is pivotal to prevent stroke associated with NVAF. ${ }^{35-38}$ Although overall adherence has not definitively been shown to be associated with stroke risk, gaps in therapy during treatment with warfarin has been 
shown to impart increased risk of stroke. ${ }^{38}$ Gaps in therapy can include missed doses, as well as delays in filling subsequent prescriptions. While individual missed doses could not be assessed in these data, we observed the number of gaps for each treatment group and showed that rivaroxaban was associated with fewer gaps compared with the other treatments. While we assessed longer gaps of 15, 30, and 60 days, even small gaps or missed doses while on NOACs can be high risk, considering the short half-lives of these medications. ${ }^{6}$ Thus, while the choice of initial NOAC did not dramatically influence overall adherence to OACs, small interruptions in therapy could still be detrimental for clinical outcomes.

This point is made in light of a recent comparative effectiveness study by Graham et al. (2016). ${ }^{39}$ This study, published in a leading clinical journal, used sound pharmacoepidemiological techniques to compare rivaroxaban and dabigatran on effectiveness and safety outcomes. Overall, there were no significant differences in effectiveness, with large differences observed in safety outcomes, which showed dabigatran to be the safer medication. The implications of the work suggest that dabigatran may be the preferred option because of its favorable net clinical benefit. However, the analysis was designed as a formal comparative effectiveness study, and as such, certain censoring criteria likely affected the results. Mainly, patients with gaps in therapy of 3 days or who switched to another therapy were censored. Thus, based on the results from this study and previous studies, ${ }^{14,19}$ the censoring criteria would have a stronger effect on the dabigatran group, that is, more dabigatran users would be censored, potentially leaving a biased dabigatran user group to compare with rivaroxaban users.

Identification of the most effective chemical entity is a moot point if most patients discontinue therapy in a matter of months. Incorporating real-world patient behaviors, including adherence, persistence, compliance, and switching, is important to inform clinicians and decision makers of the real-world effectiveness of these therapies. Future comparative studies should incorporate time-varying confounding through more advanced modeling to account for the influence censoring may have had on the Graham et al. study.

Adherence to NOACs is poised to become an important policy issue for managed care companies in the United States, since the PQA has developed a quality metric for this measure. PQA adherence measures exist for other medication classes, such as diabetes and hypercholesterolemia, and have been incorporated as standardized metrics to compare health plan and physician quality. ${ }^{40}$ For Medicare Part D and Medicare Advantage plans, these measures are given a significant weight in star ratings calculation. ${ }^{41}$ Since enrollee selection of plans and reimbursement are tied to these star ratings, health plans are strongly motivated to develop interventions to increase their ratings, such as enrollee-directed interventions or formulary management decisions. ${ }^{42,43}$ Furthermore, in practices where payment is tied to provider performance, these measures may also affect prescribers and make our study more important as a guiding help in making prescribing choices. It is encouraging, however, that treatment rates among NVAF patients seem to have increased since the introduction of NOACs to the market. ${ }^{44}$ Efforts to improve adherence with continued increasing treatment rates concordant with guideline recommendations are needed. ${ }^{45}$

\section{Limitations}

This study is subject to the limitations of all claims-based studies. ${ }^{46,47}$ Notably for this adherence study, the data captured prescription use and assumed that a patient consumed the medication and was compliant with the dosing regimen, although this cannot be confirmed. We did not incorporate patients who initiated warfarin, since it is well understood that warfarin therapy is wrought with high discontinuation rates and poor adherence. Furthermore, previous work currently in review showed that there are more differences between warfarin and NOAC users in the post-NOAC era that could have potentially biased these results.

Anecdotal evidence suggests that many providers prescribe warfarin for more complicated patient cases or for patients who require frequent visits, which would have further biased any results with warfarin. Our patient selection involved 3 time periods of continuous eligibility to be included in the analysis. This requirement was included in order to have standardized follow-up times between patients and to reduce the effect of time-varying confounding on the adherence measures. ${ }^{48}$ This selection criteria will have mostly removed those who died during follow-up, as well as those who disenrolled from their health plans. Thus, the measure of adherence does not account for these groups of patients. ${ }^{49}$ However, previous studies have shown that those who die during initial NVAF treatment have similar adherence to those who survive. ${ }^{11}$ We restricted the analysis to 9 months after diagnosis to allow sufficient followup for adherence calculation.

Finally, the study findings are applicable to the commercially insured or to those with Medicare supplemental retiree coverage and may not be generalizable to the uninsured or patients with public or government insurance, such as those with Medicare fee-for-service plans.

\section{Conclusions}

In this study of newly diagnosed, treatment-naive NVAF patients, those initiating anticoagulation therapy with dabigatran had lower adherence and more switching during 3, 6, and 9 months of follow-up compared with rivaroxaban and apixaban users. Overall adherence, as measured by PDC, to any anticoagulation therapy among those with increased stroke risk was also similar for rivaroxaban and apixaban and lower for dabigatran users. Rivaroxaban users were more likely 


\section{Adherence to Rivaroxaban, Dabigatran, and Apixaban for Stroke Prevention for Newly Diagnosed and Treatment-Naive Atrial Fibrillation Patients: An Update Using 2013-2014 Data}

to have high adherence ( $\mathrm{PDC} \geq 0.80$ ) in adjusted analyses. Factors associated with adherence in this study included older age and comorbid hypertension and diabetes. Because adherence to NOACs is a potential future quality of care indicator, managed care plans and prescribers should be aware of the variable adherence rates between treatment options.

\section{Authors}

JOSHUA D. BROWN, PharmD, PhD, Institute for Pharmaceutical Outcomes \& Policy, Department of Pharmacy Practice E Science, University of Kentucky College of Pharmacy, Lexington, and Department of Pharmaceutical Outcomes \& Policy, University of Florida College of Pharmacy, Gainesville. ANAND R. SHEWALE, MS, Division of Pharmaceutical Evaluation \& Policy, University of Arkansas for Medical Sciences, Little Rock, and JEFFERY C. TALBERT, PhD, Institute for Pharmaceutical Outcomes E Policy, Department of Pharmacy Practice E Science, University of Kentucky College of Pharmacy, Lexington.

AUTHOR CORRESPONDENCE: Joshua D. Brown, PharmD, PhD, 1225 Center Dr., HPNP \#3320, Gainesville, FL 32610.

Tel.: 352.294.8593; E-mail: joshua.brown@ufl.edu.

\section{DISCLOSURES}

This project was supported by the National Center for Advancing Translational Sciences, National Institutes of Health, through grant number UL1TR000117. The content is solely the responsibility of the authors and does not necessarily represent the official views of the NIH. The authors have nothing to disclose.

Study concept and design were contributed by Brown and Shewale. Brown and Talbert collected the data, and data analysis was performed primarily by Brown, along with Shewale and Talbert. The manuscript was written primarily by Brown, along with Shewale, and revised by all the authors.

\section{REFERENCES}

1. Desai NR, Krumme AA, Schneeweiss S, et al. Patterns of initiation of oral anticoagulants in patients with atrial fibrillation-quality and cost implications. Am J Med. 2014;127(11):1075-82.el.

2. Ruff CT, Giugliano RP, Braunwald E, et al. Comparison of the efficacy and safety of new oral anticoagulants with warfarin in patients with atrial fibrillation: a meta-analysis of randomised trials. Lancet. 2014;383(9921):955-62.

3. Schneeweiss S, Gagne JJ, Patrick AR, Choudhry NK, Avorn J. Comparative efficacy and safety of new oral anticoagulants in patients with atrial fibrillation. Circ Cardiovasc Qual Outcomes. 2012;5(4):480-86.

4. Adam SS, McDuffie JR, Ortel TL, Williams JW Jr. Comparative effectiveness of warfarin and new oral anticoagulants for the management of atrial fibrillation and venous thromboembolism: a systematic review. Ann Intern Med. 2012;157(11):796-807.

5. Chan L, Pisano M. Edoxaban (savaysa): a factor Xa inhibitor. P T. 2015; 40(10):651-55, 695.

6. Rosanio S, Keylani AM, D'Agostino DC, DeLaughter CM, Vitarelli A. Pharmacology, benefits, unaddressed questions, and pragmatic issues of the newer oral anticoagulants for stroke prophylaxis in non-valvular atrial fibrillation and proposal of a management algorithm. Int J Cardiol. 2014;174(3):471-83.
7. Andrade JG, Krahn AD, Skanes AC, Purdham D, Ciaccia A, Connors S. Values and preferences of physicians and patients with nonvalvular atrial fibrillation who receive oral anticoagulation therapy for stroke prevention. Can J Cardiol. 2016;32(6):747-53.

8. Laliberte F, Cloutier M, Nelson WW, et al. Real-world comparative effectiveness and safety of rivaroxaban and warfarin in nonvalvular atrial fibrillation patients. Curr Med Res Opin. 2014;30(7):1317-25.

9. Fang MC, Go AS, Chang Y, et al. Warfarin discontinuation after starting warfarin for atrial fibrillation. Circ Cardiovasc Qual Outcomes. 2010;3(6):624-31.

10. Castellucci LA, Shaw J, van der Salm K, et al. Self-reported adherence to anticoagulation and its determinants using the Morisky Medication Adherence Scale. Thromb Res. 2015;136(4):727-31.

11. Forslund T, Wettermark B, Hjemdahl P. Comparison of treatment persistence with different oral anticoagulants in patients with atrial fibrillation. Eur J Clin Pharmacol. 2016;72(3):329-38.

12. Martinez C, Katholing A, Wallenhorst C, Freedman SB. Therapy persistence in newly diagnosed non-valvular atrial fibrillation treated with warfarin or NOAC. A cohort study. Thromb Haemost. 2015;115(1):31-39.

13. McHorney CA, Crivera C, Laliberte F, et al. Adherence to non-vitaminK-antagonist oral anticoagulant medications based on the pharmacy quality alliance measure. Curr Med Res Opin. 2015;31(12):2167-73.

14. Crivera C, Nelson WW, Bookhart B, et al. Pharmacy quality alliance measure: adherence to non-warfarin oral anticoagulant medications. Curr Med Res Opin. 2015;31(10):1889-95.

15. Zalesak M, Siu K, Francis K, et al. Higher persistence in newly diagnosed nonvalvular atrial fibrillation patients treated with dabigatran versus warfarin. Circ Cardiovasc Qual Outcomes. 2013;6(5):567-74.

16. Vrijens B, Heidbuchel H. Non-vitamin K antagonist oral anticoagulants: considerations on once- vs. twice-daily regimens and their potential impact on medication adherence. Europace. 2015;17(4):514-23.

17. Vrijens B, Urquhart J. From monitoring to vigilance about patient adherence to new oral anticoagulants. Europace. 2014;16(1):149.

18. National Quality Measures Clearinghouse. Proportion of days covered (PDC): percentage of patients who filled at least two prescriptions for a nonwarfarin oral anticoagulant on two unique dates of service at least 180 days apart, received greater than 60 days supply of the medication, and who met the PDC threshold of $80 \%$ during the measurement period. Measure summary. NQMC:009248. July 2015. Available at: https://www.qualitymeasures. ahrq.gov/summaries/summary/47502/proportion-of-days-covered-pdc-percentage-of-patients-who-filled-at-least-two-prescriptions-for-a-nonwarfarinoral-anticoagulant-on-two-unique-dates-of-service-at-least-180-days-apartreceived-greater-than-60-days-supply-of-the-medication-and-who-met-thepdc-t?q=Heparin+therapy. Accessed July 11, 2017.

19. Brown JD, Shewale AR, Talbert JC. Adherence to rivaroxaban, dabigatran, and apixaban for stroke prevention in incident, treatment-naive nonvalvular atrial fibrillation. J Manag Care Spec Pharm. 2016;22(11):1319-29. Available at: http://www.jmcp.org/doi/10.18553/jmcp.2016.22.11.1319.

20. Shewale A, Johnson J, Li C, Nelsen D, Martin B. Variation in anticoagulant recommendations by the guidelines and decision tools among patients with atrial fibrillation. Healthcare (Basel). 2015;3(1):130-45.

21. Lauffenburger JC, Farley JF, Gehi AK, Rhoney DH, Brookhart MA, Fang G. Factors driving anticoagulant selection in patients with atrial fibrillation in the United States. Am J Cardiol. 2015;115(8):1095-101.

22. Pauly NJ, Talbert JC, Brown J. Low-cost generic program use by medicare beneficiaries: implications for medication exposure misclassification in administrative claims data. J Manag Care Spec Pharm. 2016;22(6):741-51. Available at: http://www.jmcp.org/doi/10.18553/jmcp.2016.22.6.741.

23. Pauly NJ, Brown JD. Prevalence of low-cost generic program use in a nationally representative cohort of privately insured adults. J Manag Care Spec Pharm. 2015;21(12):1162-70. Available at: http://www.jmcp.org/doi/ full/10.18553/jmcp.2015.21.12.1162. 
24. Lakshminarayan K, Solid CA, Collins AJ, Anderson DC, Herzog CA. Atrial fibrillation and stroke in the general Medicare population: a 10-year perspective (1992 to 2002). Stroke. 2006;37(8):1969-74.

25. Lip GY, Nieuwlaat R, Pisters R, Lane DA, Crijns HJ. Refining clinical risk stratification for predicting stroke and thromboembolism in atrial fibrillation using a novel risk factor-based approach: the Euro Heart Survey on Atrial Fibrillation. Chest. 2010;137(2):263-72.

26. Pisters R, Lane DA, Nieuwlaat R, de Vos CB, Crijns HJ, Lip GY. A novel user-friendly score (HAS-BLED) to assess 1-year risk of major bleeding in patients with atrial fibrillation: the Euro Heart Survey. Chest. 2010;138(5):1093-100.

27. Quan H, Sundararajan V, Halfon P, et al. Coding algorithms for defining comorbidities in ICD-9-CM and ICD-10 administrative data. Med Care. 2005;43(11):1130-39.

28. You JJ, Singer DE, Howard PA, et al. Antithrombotic therapy for atrial fibrillation: Antithrombotic Therapy and Prevention of Thrombosis, 9th ed: American College of Chest Physicians Evidence-Based Clinical Practice Guidelines. Chest. 2012;141(2 Suppl):e531S-75S.

29. January CT, Wann LS, Alpert JS, et al. 2014 AHA/ACC/HRS guideline for the management of patients with atrial fibrillation: a report of the American College of Cardiology/American Heart Association Task Force on Practice Guidelines and the Heart Rhythm Society. J Am Coll Cardiol. 2014;64(21):el-76.

30. Beyer-Westendorf J, Forster K, Ebertz F, et al. Drug persistence with rivaroxaban therapy in atrial fibrillation patients-results from the dresden noninterventional oral anticoagulation registry. Europace. 2015;17(4):530-38.

31. Hanemaaijer S, Sodihardjo F, Horikx A, et al. Trends in antithrombotic drug use and adherence to non-vitamin $\mathrm{K}$ oral anticoagulants in the Netherlands. Int J Clin Pharm. 2015;37(6):1128-35.

32. Bytzer P, Connolly SJ, Yang S, et al. Analysis of upper gastrointestinal adverse events among patients given dabigatran in the RE-LY trial. Clin Gastroenterol Hepatol. 2013;11(3):246-52.el-5.

33. Artang R, Rome E, Nielsen JD, Vidaillet HJ. Meta-analysis of randomized controlled trials on risk of myocardial infarction from the use of oral direct thrombin inhibitors. Am J Cardiol. 2013;112(12):1973-79.

34. Mak K. Coronary and mortality risk of novel oral antithrombotic agents: a meta-analysis of large randomised trials. BMJ Open. 2012;2(5):e001592.

35. Thorne K, Jayathissa S, Dee $S$, et al. Adherence and outcomes of patients prescribed dabigatran (pradaxa) in routine clinical practice. Intern Med J. 2014:44(3):261-65.

36. Ewen S, Rettig-Ewen V, Mahfoud F, Bohm M, Laufs U. Drug adherence in patients taking oral anticoagulation therapy. Clin Res Cardiol. 2014;103(3):173-82.
37. Casciano JP, Dotiwala ZJ, Martin BC, Kwong WJ. The costs of warfarin underuse and nonadherence in patients with atrial fibrillation: a commercial insurer perspective. J Manag Care Pharm. 2013;19(4):302-16. Available at: http://www.jmcp.org/doi/10.18553/jmcp.2013.19.4.302.

38. Spivey CA, Liu X, Qiao Y, et al. Stroke associated with discontinuation of warfarin therapy for atrial fibrillation. Curr Med Res Opin. 2015;31(11):2021-29.

39. Graham DJ, Reichman ME, Wernecke M, et al. Stroke, bleeding, and mortality risks in elderly Medicare beneficiaries treated with dabigatran or rivaroxaban for nonvalvular atrial fibrillation. JAMA Intern Med. 2016;176(11):1662-71.

40. Pharmacy Quality Alliance. PQA performance measures. June 15, 2015. Available at: http://pqaalliance.org/measures/default.asp. Accessed July 11, 2017.

41. Academy of Managed Care Pharmacy, American Pharmacists Association. Medicare star ratings: stakeholder proceedings on community pharmacy and managed care partnerships in quality. J Am Pharm Assoc (2003). 2014:54(3):228-40.

42. Erickson SC, Leslie RS, Patel BV. Is there an association between the high-risk medication star ratings and member experience CMS star ratings measures? J Manag Care Spec Pharm. 2014;20(11):1129-36. Available at: http://www.jmcp.org/doi/10.18553/jmcp.2014.20.11.1129.

43. Reid RO, Deb P, Howell BL, Shrank WH. Association between Medicare Advantage plan star ratings and enrollment. JAMA. 2013;309(3):267-74.

44. Brown JD, Shewale AR, Dherange P, Talbert JC. A comparison of oral anticoagulant use for atrial fibrillation in the pre- and post-DOAC eras. Drugs Aging. 2016;33(6):427-36.

45. Brown JD, Shewale AR, Dherange P, Talbert JC. Anticoagulation treatment for stroke prevention in atrial fibrillation is increasing, but further improvements needed. J Am Coll Cardiol. 2016;68(22):2492.

46. Schneeweiss S, Avorn J. A review of uses of health care utilization databases for epidemiologic research on therapeutics. J Clin Epidemiol. 2005;58(4):323-37.

47. Zhan C, Miller MR. Administrative data based patient safety research: a critical review. Qual Saf Health Care. 2003;12 (Suppl 2):ii58-63.

48. Zhou M, Chang HY, Segal JB, Alexander GC, Singh S. Adherence to a novel oral anticoagulant among patients with atrial fibrillation. J Manag Care Spec Pharm. 2015;21(11):1054-62. Available at: http://www.jmcp.org/doi/ full/10.18553/jmcp.2015.21.11.1054.

49. Gorst-Rasmussen A, Skjoth F, Larsen TB, Rasmussen LH, Lip GY, Lane DA. Dabigatran adherence in atrial fibrillation patients during the first year after diagnosis: a nationwide cohort study. J Thromb Haemost. 2015;13(4):495-504. 


\section{APPENDIX A Operational Definitions Used to Determine Patient Characteristics}

\section{Condition}

Atrial fibrillation

Coronary artery bypass surgery

Pericardial surgery

Structural cardiac repair

Mitral stenosis or prosthetic heart valve

Mitral or aortic valve repair or replacement

Concomitant hyperthyroidism or thyrotoxicosis

Prior stroke/transient ischemic attack

Congestive heart failure

Diabetes mellitus

Hypertension

Vascular diseases
Definition

ICD-9-CM diagnosis: 427.31

ICD-9-CM procedures: 36.10 to 36.19

ICD-9-CM procedure: 37.10 to $37.12,37.31$ to $37.33,37.40$

ICD-9-CM procedure: 35.00 to $35.04,35.31$ to 35.39 .35 .41 to $35.42,35.50$ to $35.56,35.60$ to 35.63 , or 35.70 to 35.73

ICD-9-CM diagnosis: $394.0,394.2,396.0,396.1,396.8, \mathrm{~V} 43.3, \mathrm{~V} 42.2$

ICD-9-CM procedure: 35.10 to 35.14 or 35.20 to 35.28

ICD-9-CM diagnosis: 242.0 to 242.9 or methimazole or propylthiouracil use (codes below)

ICD-9-CM diagnosis: 433.xx, 434.xx, 435.0, 435.1, 435.2, 435.3, 435.8, 435.9

ICD-9-CM diagnosis: 398.91, 402.01, 402.11, 425.1, 425.4, 425.7, 428.X

ICD-9-CM diagnosis: 250.x

ICD-9-CM diagnosis: 401.x, 402.x, 403.x, 404.x, 405

ICD-9-CM diagnosis: 410, 411, 412, 413, 414, 440, 441, 442, 443, 444, 445 OR

Procedure codes: 00.66, 36.0, 36.1, 39.25, 33510-33545, 34051, 34151, 34201, 34203, 34800-34834

34900, 35081-35103, 35131, 35132, 35141, 35142, 35151, 35152, 35331, 35341, 35351, 35355, 35361

$35363,35371,35372,35381,35450,35452,35454,35456,35459,35470,35471,5472,35473,35474$,

$35480,35481,35482,35483$, 35485, 35490, 35491, 35492, 35493, 35495, 35521, 35531, 35533, 35541,

$35546,35548,35549,35551,35556,35558,35563,35565,35566,35571,35583,35585,35587,35621$,

35623, 35646, 35647, 35651, 35654, 35656, 35661, 35663, 35665, 35666, 35671, 92980, 92981, 92982, 92984

Prior bleeding

ICD-9-CM diagnosis: 423.0, 430.xx, 431.xx, 432.xx, 852.0x, 852.2x, 852.4x, 853.0x, 455.2, 455.5,

$455.8,456.0,456.20,459.0,530.7,530.82,531.00,531.01,531.20,531.21,531.40,531.41,531.60$,

$531.61,533.01,533.20,533.21,533.40,533.41,533.60,533.61,534.00,534.01,534.20,534.21,534.40$,

$534.41,534.60,534.61,535.11,535.21,535.31,535.41,535.51535 .61,537.83,562.02,562.03,562.12$,

$562.13,568.81,569.3,569.85,578,578.0,578.1,578.9,593.81,599.7,719.10,719.11,719.12,719.13$,

$719.14,719.15,719.16,719.17,719.18,719.19,784.7,784.8,786.3$

Anemia

ICD-9-CM diagnosis: 285.1, 282.41, 282.42, 282.5, 282.60-282.64, 282.68, 282.69, 280.1, 280.8, 280.9, 281.0, 281.1, 281.2, 281.3, 281.4, 281.8, 281.9, 284.0, 284.01, 284.09, 284.1, 284.8, 284.81, 284.89,

284.9, 280, 283.0, 283.1, 283.11, 283.19, 283.2, 283.9, 282.0, 282.1, 282.2 282.3, 282.4, 282.49, 282.7, $282.8,282.9,284.2,285.0,285.21,285.22,285.29,285.8,285.9$

Renal failure

ICD-9-CM diagnosis: 584, 584.5, 584.6, 584.7, 584.8, 584.9, 585, 585.3, 585.4, 585.5, 585.6, 585.9,

586, 792.5, V420, V451, V4511, V4512, V560, V561, V562, V5631, V5632, V568

ICD-9-CM codes: $272.0 \mathrm{x}-272.4 \mathrm{x}$

ICD-9-CM codes: 290.x, 294.1, 331.2

ICD-9-CM codes: 416.8, 416.9, 490.x-505.x, 506.4, 508.1 508.8

ICD-9-CM codes: 446.5, 710.0-710.4, 714.0-714.2, 714.8, 725.x

ICD-9-CM codes: $250.4-250.7$

ICD-9-CM codes: 140.x-172.x, 174.x-195.8, 200.x-208.x, 238.6

ICD-9-CM codes: 196.x-199.x

ICD-9-CM diagnosis: 291.0, 291.1, 291.2, 303, 305.0, 535.3, V11.3

Alcohol use

Medications

Warfarin

Dabigatran

Rivaroxaban

Apixaban

Aspirin

NSAIDs

Methimazole/propylthiouracil

First 6 digits of GPI code: 832000XXXXXXXX

First 6 digits of GPI code: $83337030 \mathrm{XXXXXX}$

First 6 digits of GPI code: $83370060 \mathrm{XXXXXX}$

First 6 digits of GPI code: 83370010XXXXXX

First 6 digits of GPI code: $641000 \mathrm{XXXXXXXX}$

First 6 digits of GPI code: $661000 \mathrm{XXXXXXXX}$

First 6 digits of GPI code: 283000XXXXXXXX

GPI = Generic Product Identifier; ICD-9-CM = International Classification of Diseases, Ninth Revision, Clinical Modification; NSAID=nonsteroidal anti-inflammatory drug. 
Adherence to Rivaroxaban, Dabigatran, and Apixaban for Stroke Prevention for Newly Diagnosed and Treatment-Naive Atrial Fibrillation Patients: An Update Using 2013-2014 Data

\section{APPENDIX B Study Attrition with Inclusion and Exclusion Criteria}

At least 2 AF diagnoses $\leq 30$ days apart during January 1, 2013-September 30, 2014 $\mathrm{N}=94,297$

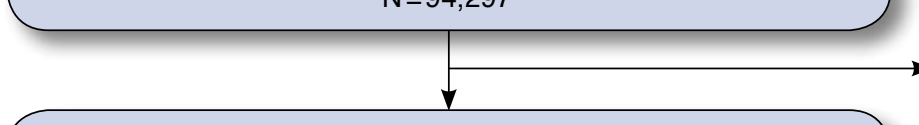

At least 12 months of continuous enrollment before first AF diagnosis (index date) $n=67,794$

No exclusion criteria during pre-index period $n=53,818$ $n=26,503$

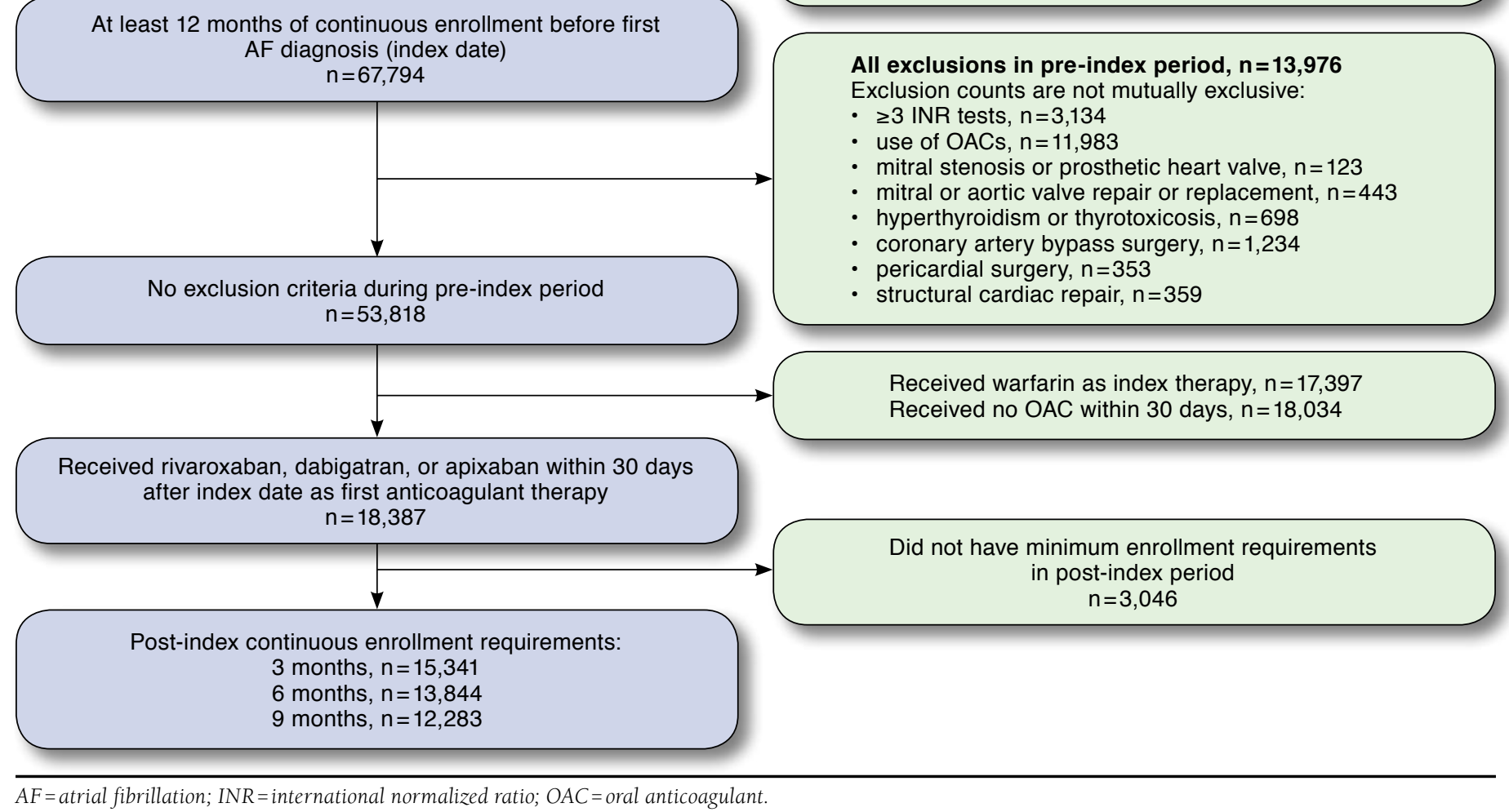

